\title{
التفسير النبوي لألفاظ العبادة
}

\section{Prophetic interpretation of the words of worship}

" د. حافظ حارث سليم

".* ت كفايت الله همدانى

\section{ABSTRACT:}

The Sunnah and Hadith of the Holy Prophet PBUH has been accepted as an important source of Islamic law, next in importance only to the Holy Quran. This status of the Sunnah has remained unchallenged and undisputed throughout the centuries. There have been many differences among Muslims in their juristic opinions, but the authority of the Holy Quran and Sunnah of the Holy Prophet PBUH was never denied by any jurist. The Holy Prophet PBUH being the best teacher employed two different ways to enlighten his companions about Islam and particularly matters of worships. On few occasions, he inquired about their prior knowledge about the topic and then illuminated it, while on other occasion, he simply exposited the spirits and essence of rites and rituals.

Key Words: Sunnah, enlighten, worship, undisputed, illuminated.

$$
\begin{aligned}
& \text { يعد الحديث النبوي الشريف من أفصح أساليب العرب وأكثرها اعجازاً ولاريب فهو كلام النبي محمد صسلى }
\end{aligned}
$$

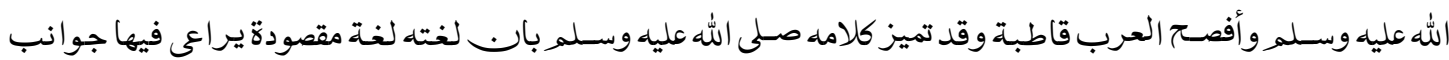

$$
\begin{aligned}
& \text { الدلالة والقصد لدى المتلقي، فهي لغة علميةتجمه بين رقة العبادةاودقة التوجيهومراعاة الجوا نب النفسية والاجتماعية }
\end{aligned}
$$

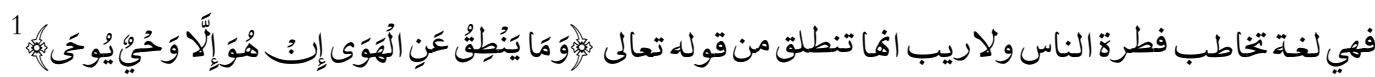

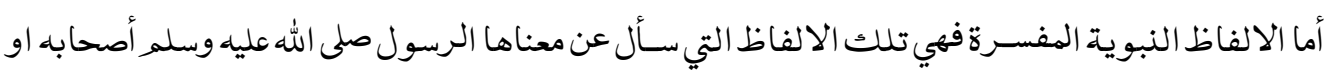

$$
\begin{aligned}
& \text { سُســل عنها فضـلاعن الالفاظ التي فسرها رسول الله صلى الله عليه وسلم في غير أسلوب الاستفهام كأبـ يذكر اللفظ ثم. } \\
& \text { يعقب بتفسير محناه. يمكن تفصيل ذلك على النحو الآتي: } \\
& \text { 1: النهط الأول: الأستعانة باسلوب الأستفهام. } \\
& \text { 2: النمط الثاني: التفسير المباشر. }
\end{aligned}
$$

\footnotetext{
*Assistant Professor, Faculty of Arabic, Govt: Postgraduate College, Murree.

${ }^{* *}$ Associate Professor, HOD Arabic, National University of Modern Languages, Islamabad.

Email: kafaitullahhamdani@gmail.com
} 


\section{النمط الأول:الاستعانة بأسلوب الاستفهام: \\ وجاء هذا الأسلوب على وفقى ما يأتي:}

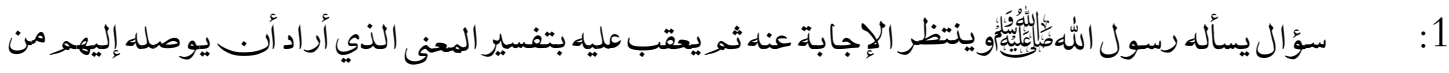

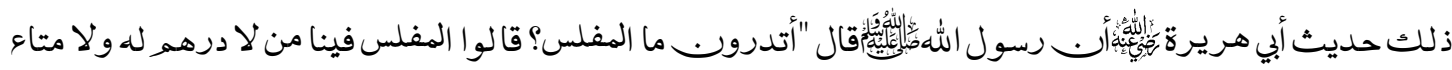
فقال المفلس من أمتي من يأتي يوم القيامة .......

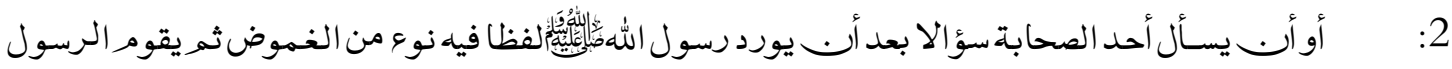

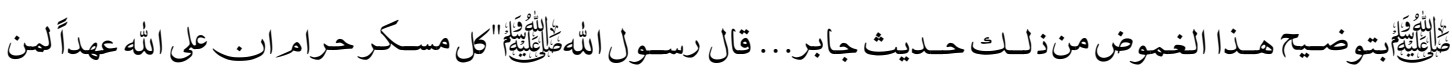

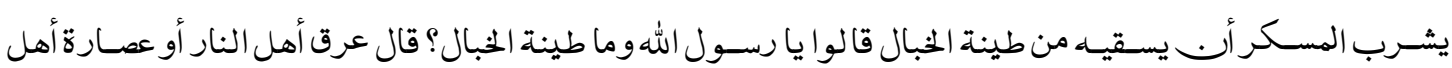

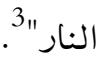

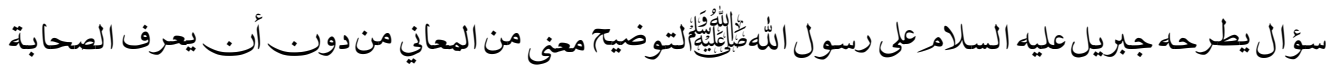
$: 3$

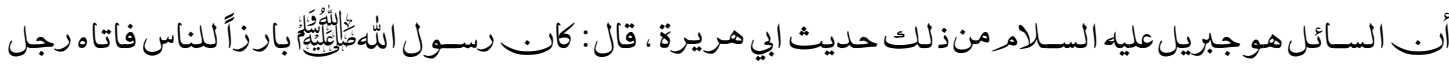

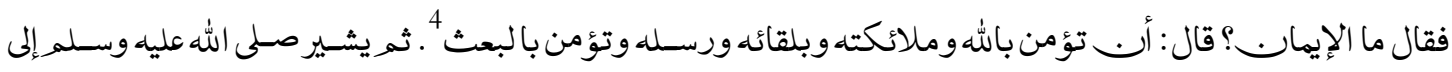

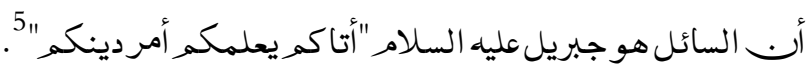
النمط الثاني :التفسير المباشر وهـذا النمط يختلف عن النوع السـابق بكونه لا يعتمد على الاسـتفهامروانها ايراد اللفظ ثم تفسـيرهوهو على أنواع:

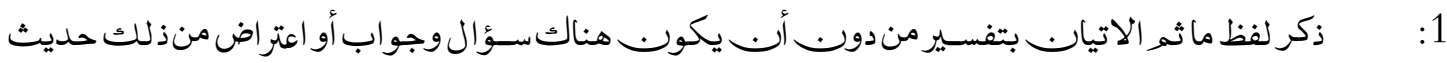

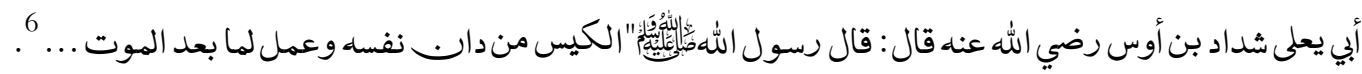

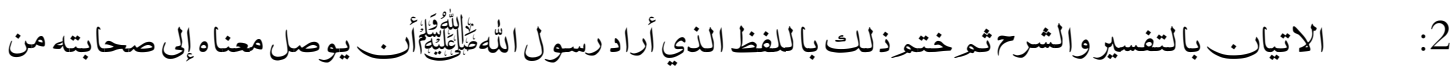

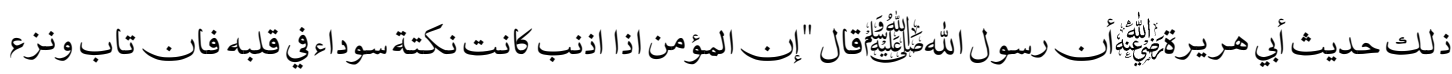

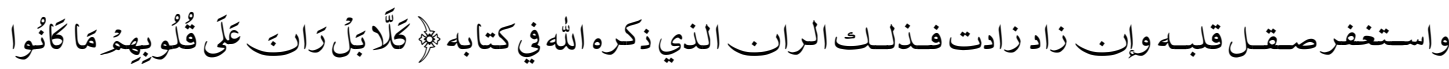

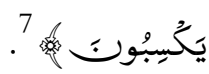

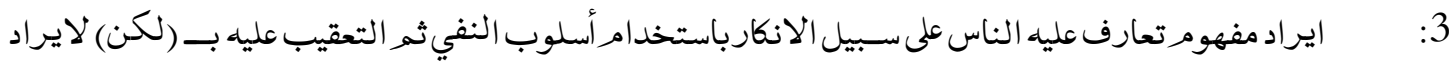

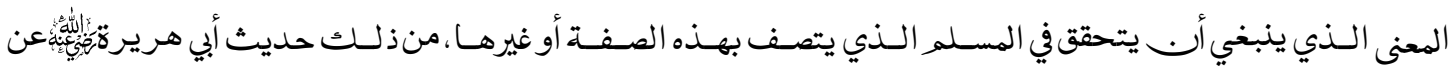




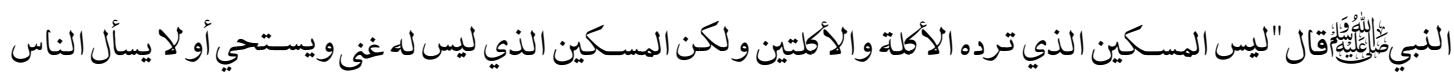
إلحافًأ

\section{المبحث الأول:الفاظ العبادة الدفسرة باسلوب الاستفهام}

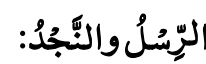

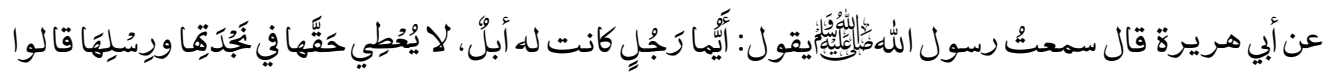

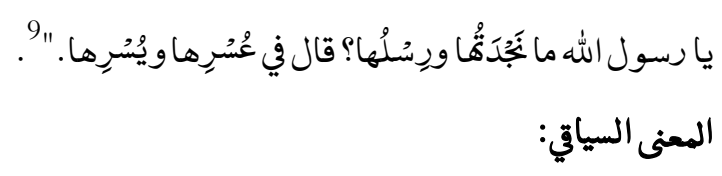

جاء هذا اللفظ في سياقتحذيرمن الإمتناء عن فعل واجب وهو إخراج الزكاةوفيه أشارة إلى أســ المسلم ينبني

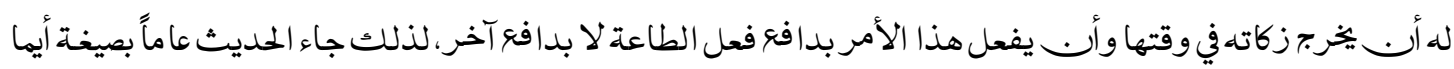
رجلٍ فيجب على المسلم أس. يخرب زكاته في كل حال سواء في حالة عسرٍ أو حالة يسٍٍ، وقد اختلف العلماء في تحديد معنى ألنجده والرسل، هل معنى النجدة هي الجذب والشدة بعينهأوسنوات السمنو الخصوبة حيث تكنزالإلبل الشحوم فيصعب

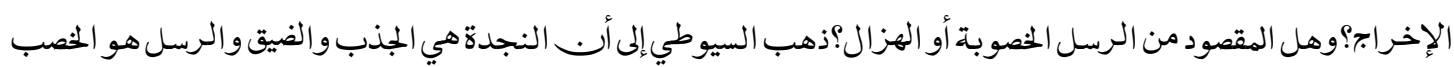

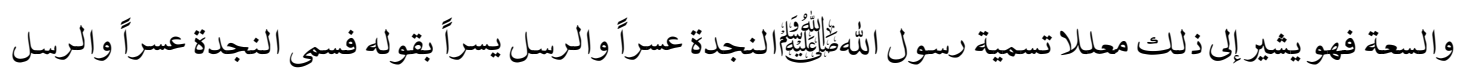
يسراً لأبَّ الجذب عسوُ والخصب يسر فهذا الرجل يعطي حقها في حال الجذب والضيق وهو المراد بالنجدة وفي حال

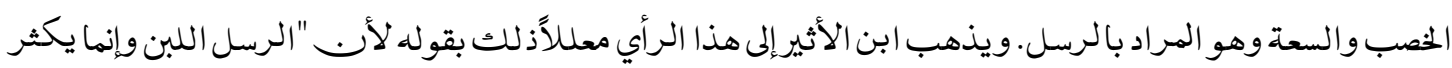

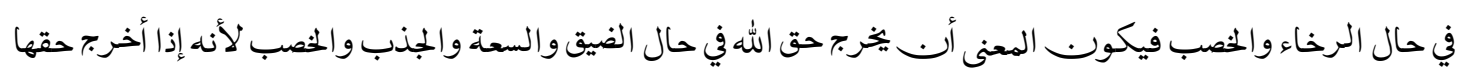

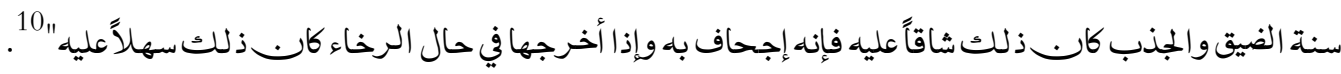
فهذا الرأي يرى أبـ إخراجا الزكاةفي أيام الجذب أصعب واشدمن أيامر الرخاءو الخصب في حين يرى قسم آخر من العلماء أبـ العكس هو الصحيح، فهذا السندي يقول "قيل النجدة الشدة أو السمن و الرسل بالكسر الهينة أي يعطي وهي سماب حسال ميشتد عليه إخراجها فتلك نجدتما ويعطي في رسلها وهي مهازيل ". ويعلل أبو عبيد ذلك باب. نجدقا أت. تكثر شحومها وتحس حتى يمنع ذلك صاحبها أب. ينحرها نفاسة بها فصار ذلك بمنزلة السلاح لها تمتنع به

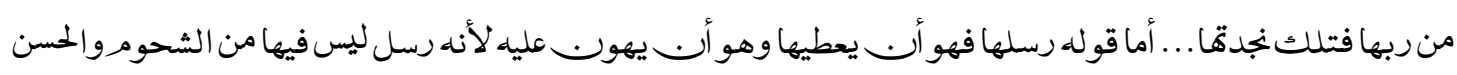

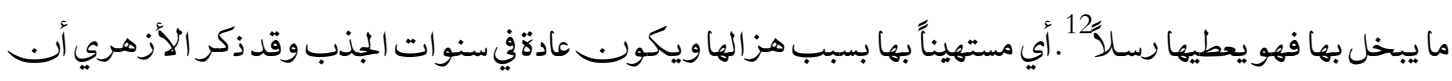
هناك من ذهب إلى أند ليس للهزال معنى في الرسل بل المعنى أنه أخرجها بطيب نفس وقد علل ذلك بأنه من بذل حق اله 


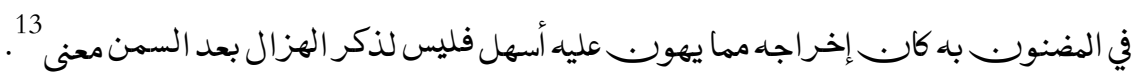

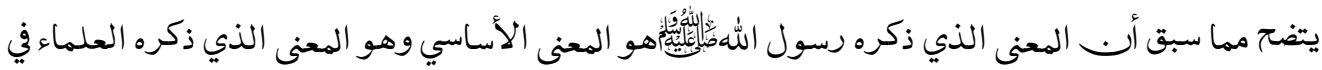
تفسير هذين اللفظين بالعسر واليسر وإلى هذا المعنى يشير أبو عبيد بقوله فمعنى الحديث أنه أراد من أعطاها في هاتين الحالتين النجدة والرسل أي مشقة النفس وعلى طيب منها 14. الرَّقُوبْ

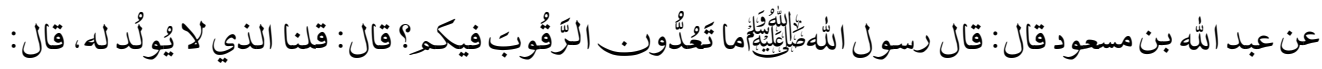

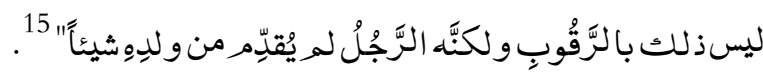
المعنى السياقي:

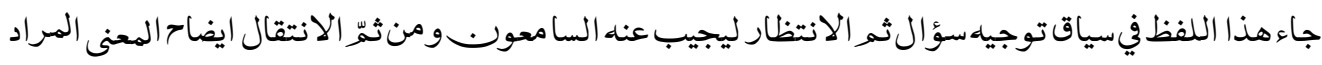

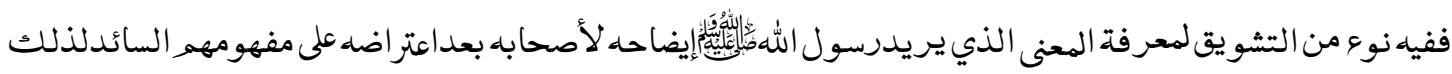
نجد أُّـ العلماء ذهبو ا في تفسير هذا اللفظ إلى معنيين مهمين ركز كل واحد منهمر على المعنى الذي وجد فيه غاية ما اراد

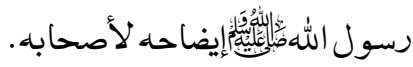

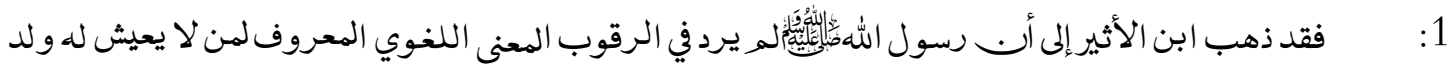

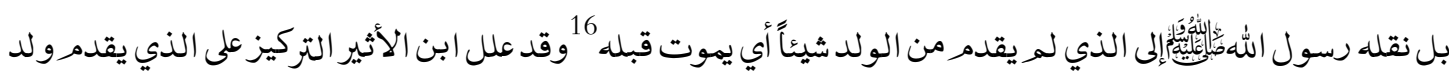

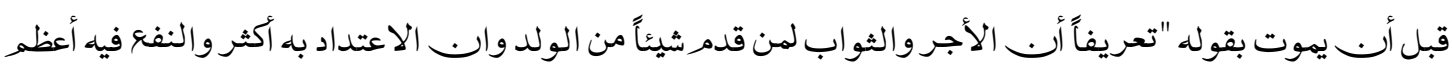

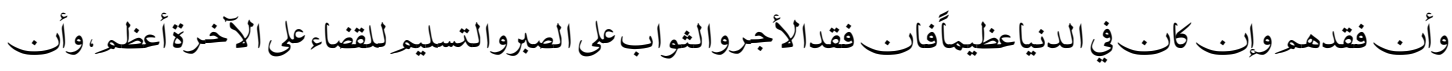
المسله ولدهفي الحقيقة من قدمه واحتسبه ومن لمريرزق ذلك فهو الذي لا ولدله 17 .والى المعنى نفسه ذهب النووي فهو

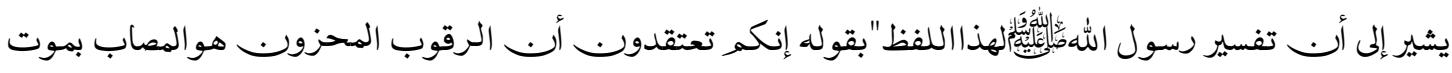
أولاده وليس هو كذلك شرعاً بل هو من له يمت أحد اولاده في حياته فيحتسبله يكتب له ثو اب مصيبته به وثواب صبره عليهويكوبـ له فرطاً وسلفًا 18. 2: وذهب الهروي إلى أبـــ المراد من الرقوب ليس فقد الأولادفي الدنيا وإنما المقصود فقدهـفي الآخرة فهو يشير إلى أرـــنظرة الناس إلى الرقوب مقتصرة على مصائب الدنيا فقط.

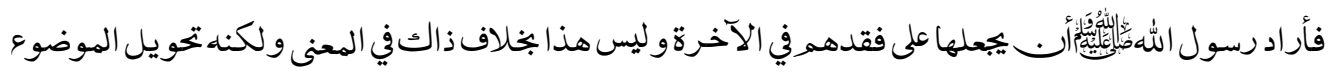

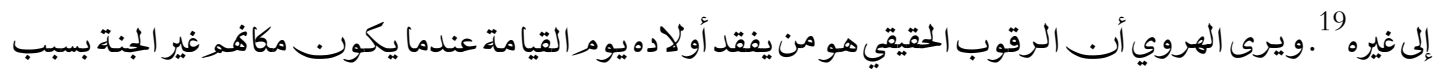




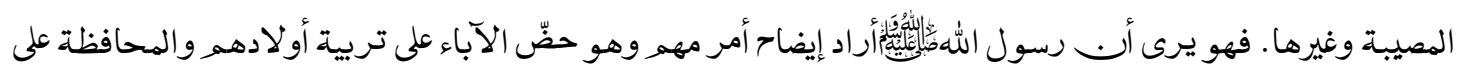
ذلك خوفاً من أبر يحرموا أولادهم يومر القيامة بسبب اقتر افهم لذنوب عظيمة والى ذلك يشير أبو عبيد الهروي ليعزز

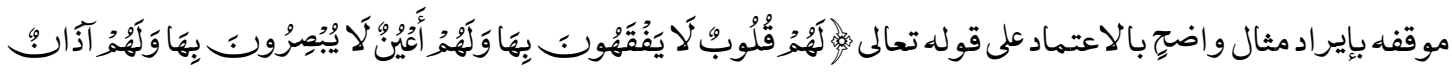

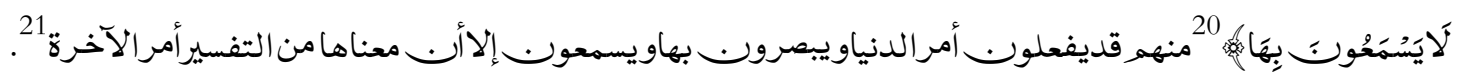
الإسلامر:

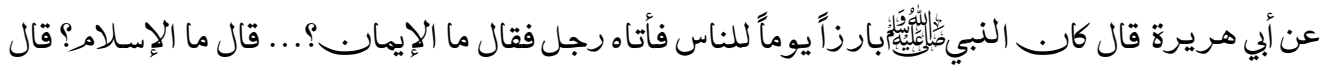

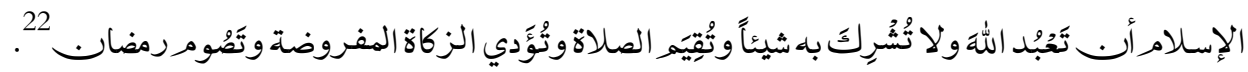
المعنى السياقي:

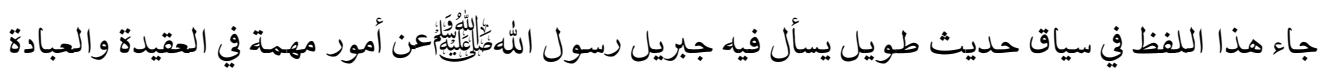

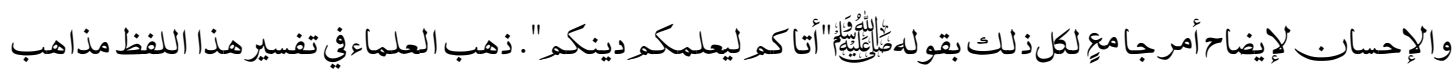

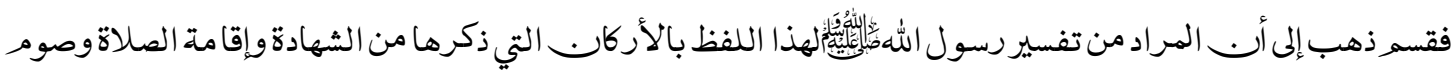

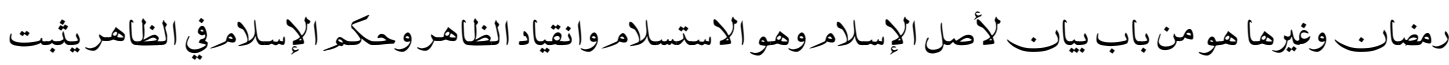
بالشهادتين وإنما أضاف لها الصلاة والزكاة والحج والصومر لكونا اظهرشعائر الإسلامووأعظمها وبقيا مها يتم استسلامه وتركة لها يشعر بانخلال قيد انقياده أو اختللاله 23.

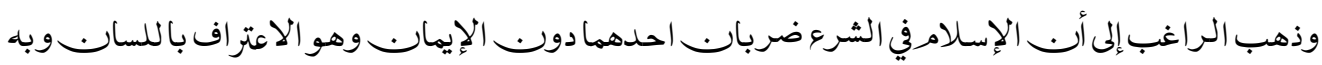

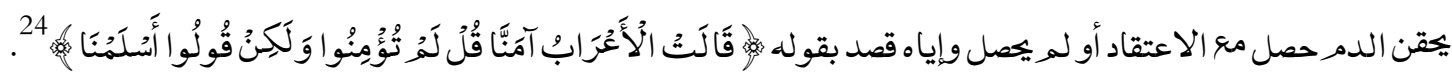

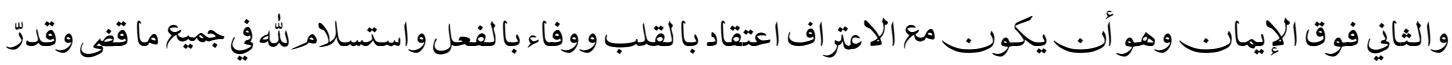

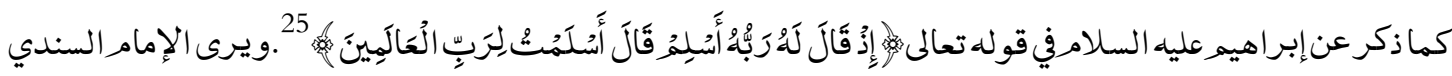

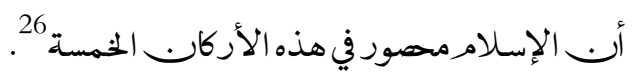

وهناك من ذهب إلى أبـــ الإسلامريتطلب ثلاثة أمور وهي توحيد الله تعالى والانقياد له بالطاعة والبراءة من الشرك وأهله بل يذهب إلى أبعدمن ذلك إذيفرق بين الاستسلام الشرعي والاستسلام القدري فيقول"أس. يستسله العبد لربه استسلاماً شرعياً وذلك بتوحيد الله وافراده بالعبادةوهذا الإسلامرهو الذي يمهد عليه العبدويثاب عليه أما

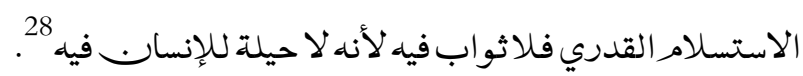
يتضح مما سبق أُـــ الإسلام لفظ عام قد يطلق على الإيماب. لـ وقد يطلق على الدين الإسلامي بأكمله وهو ما 
أشار إليه البغوي بقوله "جعل النبي الإسلام هنا اسماً لما ظهر من الأعمال والإيماس. اسم لما بطن من الاعتقاد وليس

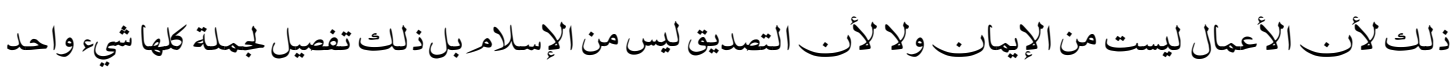

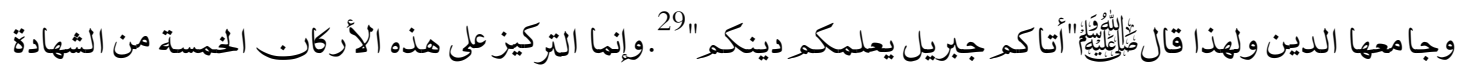

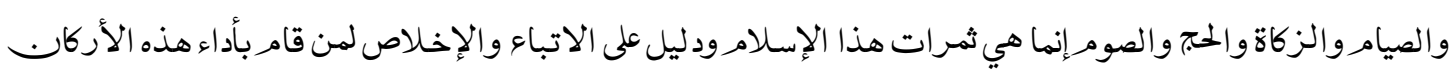
الخمسة وعدم القيام بها دليل عدم الاتباء ودليل الادعاء غير الصادق.

الكَصرَابِّ:

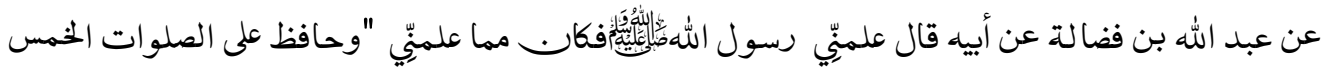

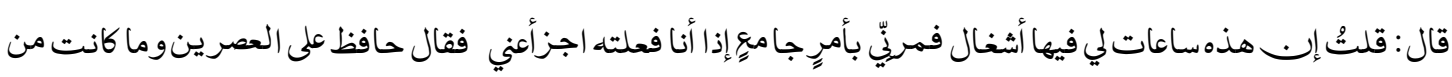

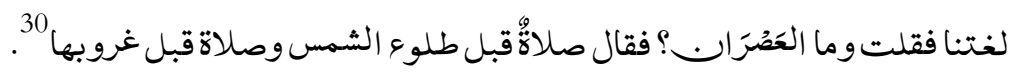

\section{المعنى السياقي:}

جاء هذا اللفظ في سياقحٍِّ على الهحافظة على أمر محبب والتركيزعليه لأهميته وخطورتهفي وقت واحدونجد أس. العلماء لم يختلفوا في معنى العصرين وإنما تركز كلامهم في سبب هذه التسمية قال الخطابي يريد بالعصرين صلاة العصروصلاة الصبح والعرب قدتخمل احد الاسمين على الآخر فتجمع بينهما في التسمية طلباً للتخفيف كقولهم العمرين

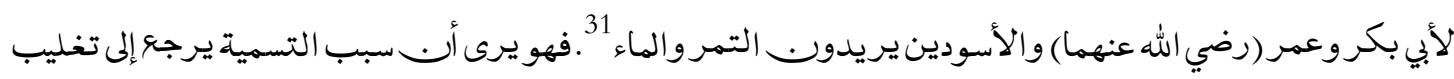

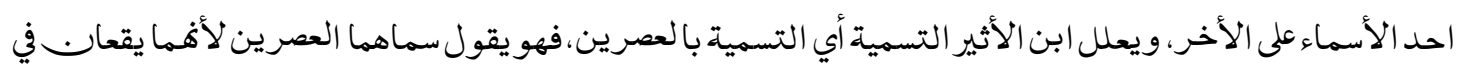

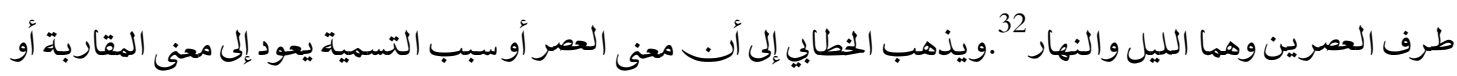
الامتداد فهو يقول "إِلـ صلاة العشي إنما سميت عصراً لالـ مدى وقتها يقارب غروب الشمس في قولهم أعصرت الجارية إذا قاربت الإدراك، ما وكذلك المعنى في تسمية صلاة الفجر عصراً وذلك إلـ الوقت الذي يصلي فيه يمتد إلى يقل طلوو الشمس أو يقاربه"

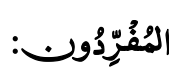

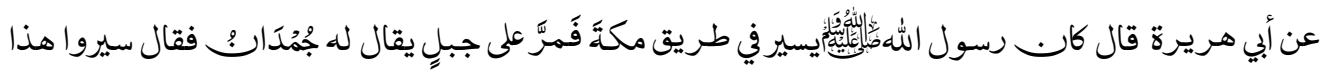

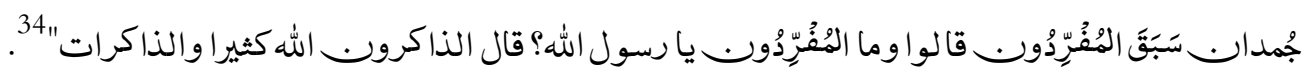

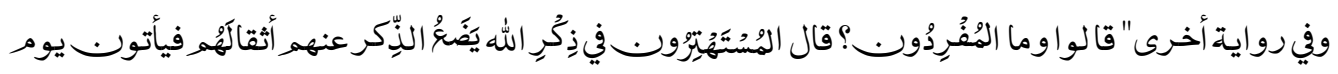




\section{المنى السياقي:}

جاء هذا اللفظ في سياق حضّ على أمر مهر متعلق بالإيماس و ومتعلق بجب الله وهو ذكر الله تعالى وجاء التركيز فيه من ناحية الاعتزال عن الناس لذكر الله تعالى وييا. السبق في ذلك لمن أدام ذكر الله تعالى. وقبل الدخول في دلالة هذا التفسير لابدمن الإشارة إلىضبط هذا اللفظ كما ذكره العلماء إذ قا لو إنهجاء بفتح

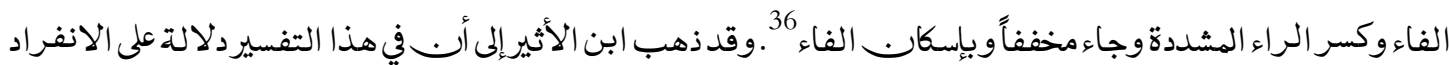
في العلم والتفقه فيه ومتابعة قضية النصح بالأمر بالمعروف و النهي عن الهنكر فهو يقول فرّد الرجل إذا تفقه واعتزل

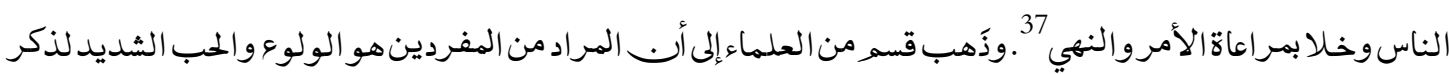

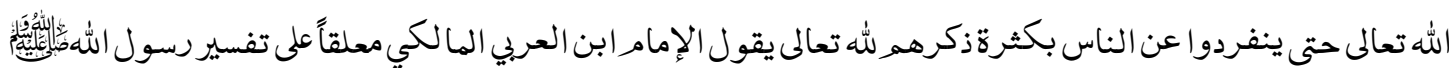

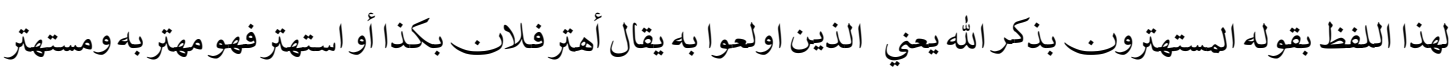

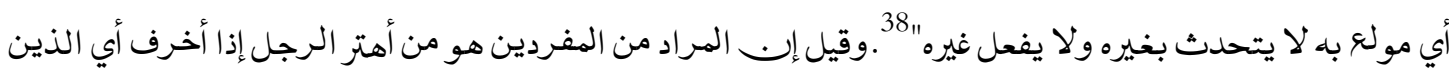

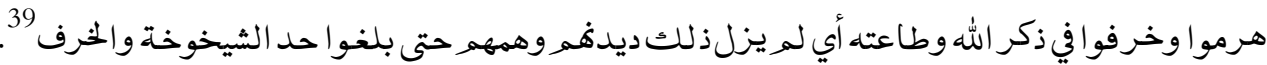

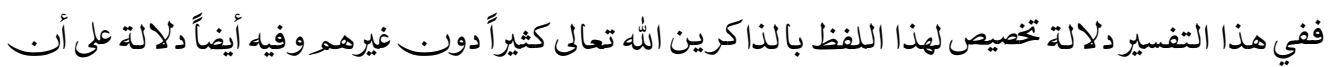

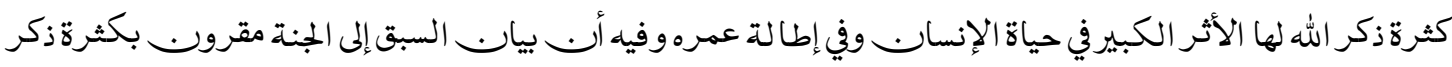
الله تعالى وأت. يكوب. ديدهم وهمهـ وشغلهـر الشاغل والله اعلد. المبحث الهاني:الفاظ العبادة الدفسرة تفسيراً مباشراً: البخيل:

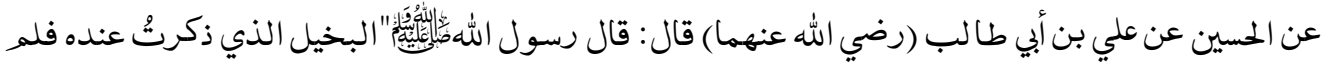

$$
\text { "يُصلَّ عليّ" المنى السياقي: }
$$

جاء هذا اللفظ في سياق التعريف الدباشر للبخيل الحقيقي الذي يستحق هذا الوصف دورغ غيره، فهو الذي لا

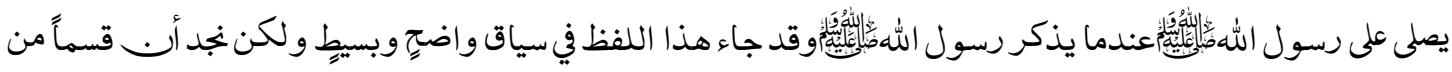

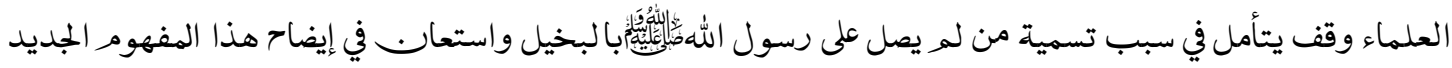
بمعنى الفاء في الحديث "فلم يُصلِ علي" وذهب الطيبي إلى "أبـ الفاء في الحديث يحتمل معنيين أثنين الأول "أبـ الفاء استبعادية والمعنى بعيد عن العاقل أس يتمكن من إجراء كلمات معدودة على لسانه فيفوز بها فلم يغتنمها فحقيق أس. 


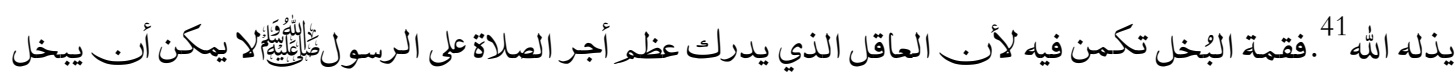

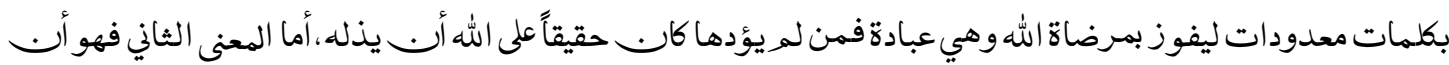

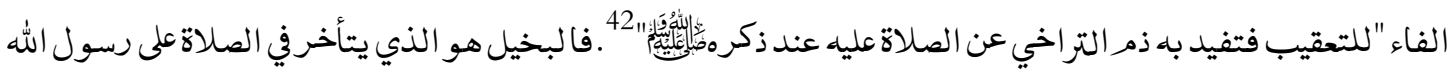

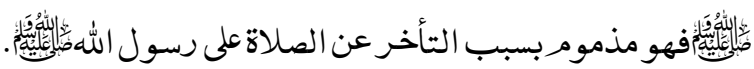

الماجز:

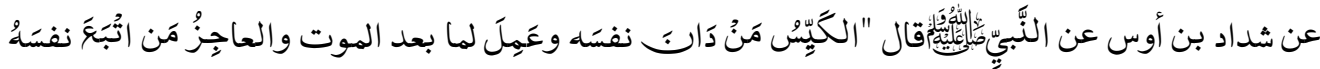

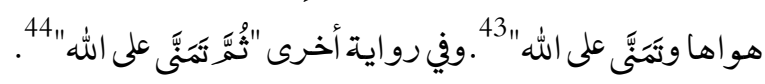
المعنى السياقي:

جاء هذا اللفظ في سياق الحديث عن معنيين متضادين وهما (الكيس والعاجز) لتبيالـ حقيقة واحدة وهي

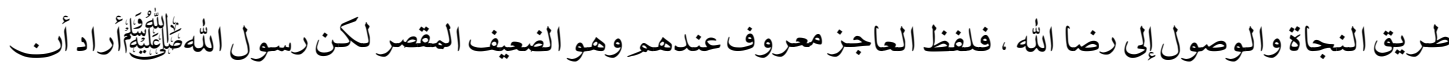
يبين لنا صفات هذا العاجزويوضح لنا الأمور التي أوصلته إلى هذا الضحف. وقد ذهب ابن العربي في إيضاح هذا اللفظ إلى أُس العاجز هو المقصرفي الأمور وذلك لأنه أتبع نفسه هواها وجعلها تابعة لهو اها فلمر يكفها عن الشهوات ولميمنعها

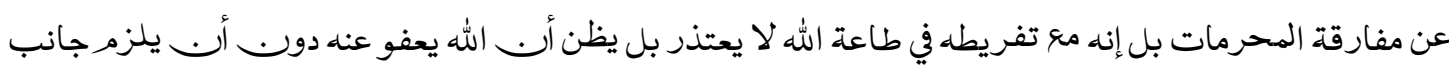
التوبتة والاستغفار"

فا لعاجز مقصر في كل الجبوانب التعبدية والعملية ويرى من شدة جهله أنه يستحق الجنة لذلك نلحظ في

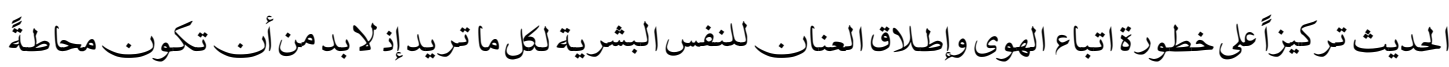

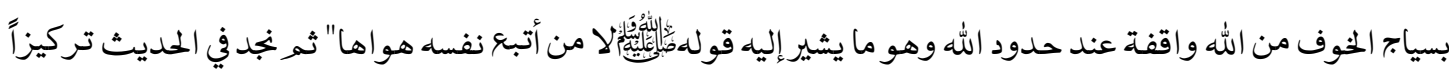

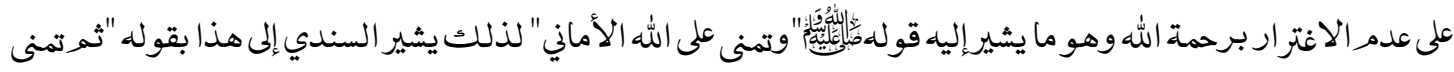
على الله الأماني بأنه كريمر غفور رحيم غني عنه وعن عمله فلا يعاقبه بل يدخله الجنة ويعطيه ما يشتهي 46 .ويشير ابن العربي إلى هذا المعنى إشارةً واضحة بقوله "وتمنى على الله أي يذنب ويتمنى الجنة من غير الاستغفار والتوبة" وفي الحديث إشارة إلى سفاهة عقل من هذا فعله وإلى هذا المعنى يشير ابن العربي "والعاجز هو السفيه" وتكمن سفاهة العقل في عدمرإدرا كه الأمور وانجر ارهور اء الشهوة متشبهاً بذلك بمن لا عقل له. الكَُِّّص:

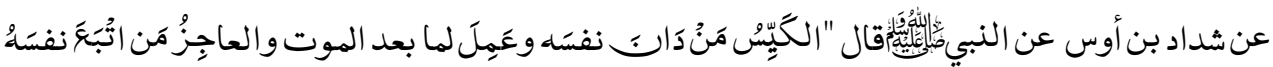


جاء هذا اللفظ في سياق التعريف المباشر للكيس وربط هذا التعريف بمراقبة النفس وعمل الصالحات قبل الموت والخروبج من الدنيا أي كأنه أراد من الكيس الرجل العاقل الحكيمر الذي يتصرف تصرفاً يليق به من أجل النجاة من عذاب الله لذلك نجد أبــ العلماء قد ذهبوا في تحديدصفات من هو العاقل الحقيقي إلى اتجاهين اثنين.

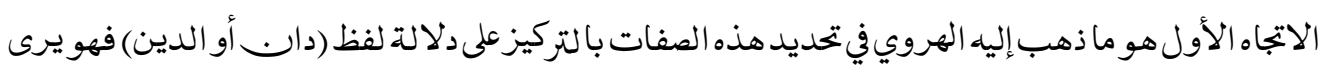

أهخاتختمل معنيين اثنين هما:

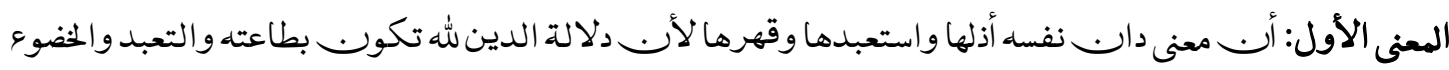
له وحده سبحانه.

المعنى الثاني:هو الحساب فمعنى(دابـنفسه) حاسبهالأبــلالة الدين تعني الحساب منذلك سمى يوم القيامة ييوم الدين أي يوم الحساب والجزاء ـأما الاتجاه الثاني فهو ما ذهب إليه ابن العربي في تحديد هذا اللفظ إلى التركيز على مسألة

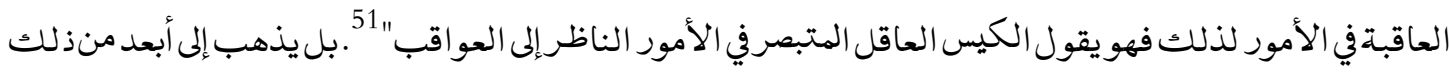
عندما يشير إلى معنى مهم وهو العمل للآخرة قبل الموت فهو يقول فالموت عاقبة أمر الدنيا فالكيس من أبصر العاقبة "52.

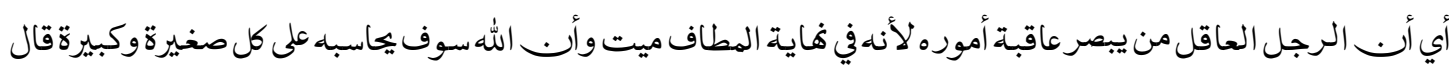

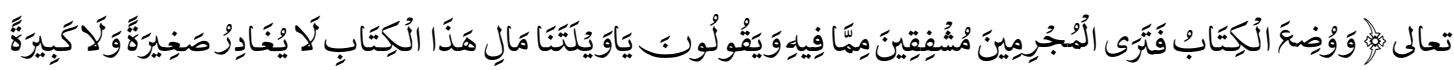

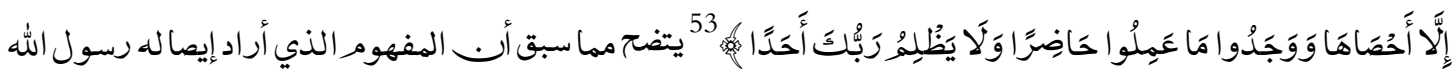

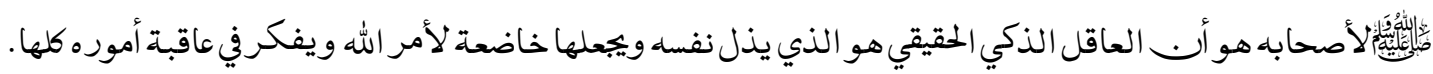

\section{الهوامش والمراجع}

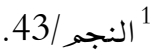

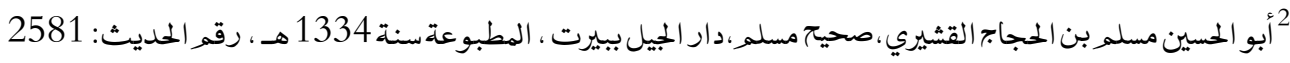

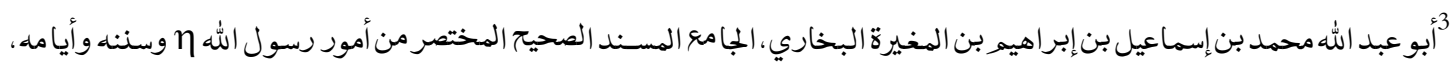
دارطوق النجاة، الطبعة الأولى 1422هـ ، رقي الحديث: 4343 4 صحيح مسلد ، أبو الحسين مسلح بن الحجاج القشيري، رقم الحديث: 9 المصدر نفسه 
أبو عبدالله محمد بن يزيد القزويني ابن ماجه،سنند ار إحياء الكتب العربية فيصلعيسى البابي الحلبي، رقم الحديث: 4260 7

8 صحيح بخاري، أبو عبدالله محمد بن اسماعيل البخاري، رقم الحديث: 1479

وأبو عبد الرحمن أحمد بن شعيب بن علي الخراساني النسائي ، سنن، المكتبة العصرية، صيدا بيروت، رقمر الحديث: 2441 10 مجدالدين أبو السعادات المبارك بن محمد الجرزي ابن الأثير، النهايتةفي غريب الحديث والأثر ، بيروت، ط1 1، جـ ص223 223 11 المصدر نفسه و نفس الصفحة 12 غريب الحديث أبوعبيد القاسم بن سلام الهروي ، دار إحياء التراث العربي، بيروت، جـ 1 ص 205-206 13 النهايتة في غريب الحديث، ابن الأثير، ج2 ص ص 223 14 15 صحيح مسلم، أبو الحسين مسلمربن الحجاج القشيري، رقهم الحديث:2608 16 النهايتة في غريب الحديث، ابن الأثير، جـ2 صلم 249 (17 المصدر نفسه و نفس الصفحة

18 محبي الدين أبو زكريايييى الخزامي،صحيح مسلم بشر حالنووي،دار إحياء التراث العربي،بيروت،ط2، 1972ه، ج16ص 162

$$
\begin{aligned}
& 19 \text { غريب الحديث، ابنسلامر الهروي، ج3 ص } 109 \\
& \text { 20 الأعراف/179 } \\
& \text { غغريب الحديث، ابنسلام الهروي، جر } 109 \\
& \text { صحيح مسلم ، أبو الحسين مسلم بن الحجاج القشيري، رقم الحديث: } 9
\end{aligned}
$$

2323مد بن علاب الصديقي الشافعي،دليل الفالحين لطرق رياض الصالحين، دار الرياب. الحديث، القاهرة، 1987م، جـ ص ص217

$$
\text { 24 الحجرات/14 محمدناعلات }
$$$$
\text { 25 }
$$

62 أبو الحسنمحمد بن عبدالهادي المعروف بالسندي،سنن المصطنى،دار الفكر ،بيروت، جر 1ص 33

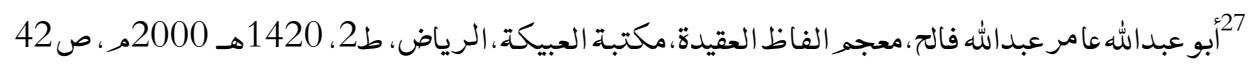
المصدر نفسه و نفس الصفحة

292 أحمد بن علي بن حجر العسقلاني، فتح الباري شر حصحيح البخاري، ،دار الكتب العلمية ، بيروت، ط1، ج 1 ص 157

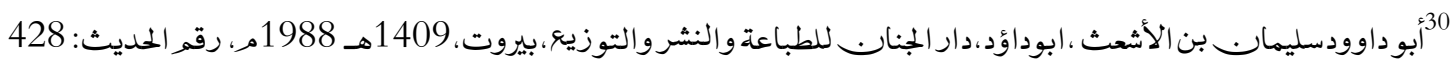
31 أحمد السهارنفوري، بذل المجهول في حل سنن أبي داوود، دار الكتب العلمية، بيروت، جـ 3ص 233 32 النهايتة في غريب الحديث، ابن الأثير، ج3 ص246 


$$
\begin{aligned}
& \text { 33 غريب الحديث، أحمد بن محمد بن إبراهيم الخطابي، دار الكتب العلمية، بيروت. بج } 1 \text { ص } 187 \\
& \text { 34 صحيح مسله، مسلمربن حجاج، رقو الحديث: } 2676
\end{aligned}
$$

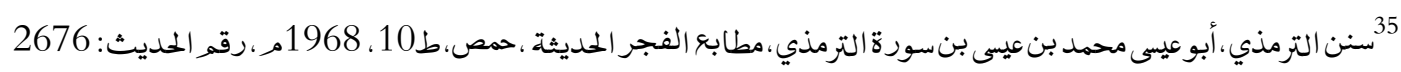

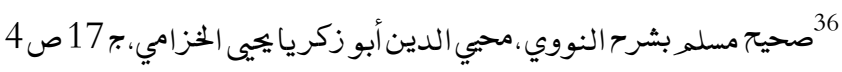

$$
\begin{aligned}
& \text { أنهاية في غريب الحديث، ابن الأثير، ج3 ص ص } 425
\end{aligned}
$$

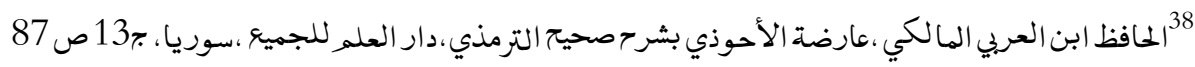

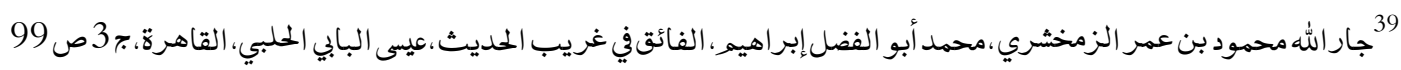

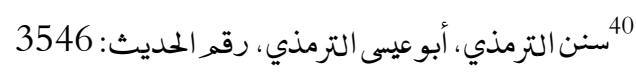

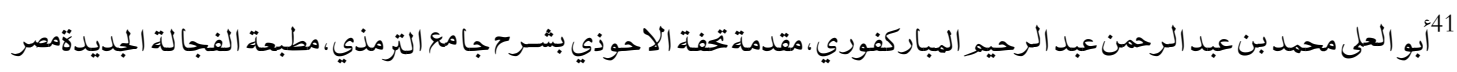

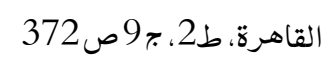$$
\text { | المصدرنفسه ونفس الصفحة }
$$

سنن التزمذي، أبوعيسى الترمذي، رقق الحديث: 2459

44سن ابن ماجه، أبو عبدالله محمد بن يزيد القزويني ابن ماجة، رقم الحديث: 4260

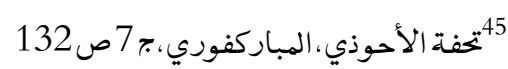

46 سنن ابن ماجه، أبو عبدالله محمد بن يزيد القزويني ابن ماجه، رقمر الحديث: 4260

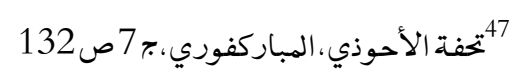

ألمعدرنفسه ونفس الصفحة

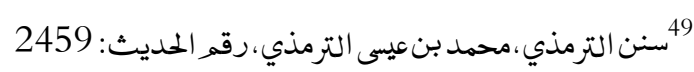

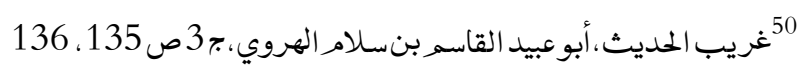

515:كفة الأحوذي، المباركفوري، بج ص ص 132

52 الهصدرنفسه ونفس الصفحة

39

\section{(@) $\odot$}

This work is licensed under a Creative Commons Attribution 4.0 International License. 